\title{
Economic and Environmental Effects of Airline Deregulation
}

\author{
Youdi Schipper and Piet Rietveld \\ Faculty of Economics \\ Free University Amsterdam
}

\begin{abstract}
This paper deals with the issue of regulatory reform in the airline industry, in connection with environmental externalities. Deregulation has led to shorter routes, higher frequencies, probably larger aircraft sizes and more intense peak traffic at airports. In addition, deregulation has led to lower average real fares, although various barriers to entry still allow carriers to keep prices above competitive levels. Environmental effects have thus far not received much attention in the discussion on deregulation. The paper contains a discussion of various types of environmental effects of aviation. An analytical model is developed to compare these effects in hub and spoke systems with a fully connected system. The conclusion is that for $\mathrm{CO}_{2}$ emissions private cost considerations and environmental considerations may run parallel in the choice of transport network, but that for other types of pollutants there may be a clear conflict. In addition the paper pays attention to equity aspects of externalities.
\end{abstract}

\section{Introduction}

Economic deregulation has been described as “... the state's withdrawal of its legal powers to direct the economic conduct (pricing, entry and exit) of nongovernmental bodies." (Winston, 1993, quoting Stigler). Regulatory reform has become a significant trend in economic policy in OECD countries since the mid-1970s, affecting in particular sectors like transportation, telecommunications, banking and financial services, broadcasting and energy supply. The airline industry stands out as an important case in this trend in economic policy: formerly an almost completely regulated sector, it has been and is still going through a process of deregulation both at the national and the international level. This paper examines changes in 
airline regulation (section 2) and discusses two types of related effects. On the one hand, there are effects on the supply side of the airline industry, in particular changes in network structure and competition, which are discussed in section 3 . These effects, it will be argued in section 4 , in turn influence the environmental impact of aviation. Section 5 concludes.

\section{Regulation and Deregulation in the Airline Industry}

After failures to reach a multilateral settlement on traffic rights, pricing and capacity in Chicago (1944) and Geneva (1947), the regulation of these three important aspects largely became a matter for bilateral negotiations of individual governments and airlines. The following system developed (Doganis 1995):

- the exchange of traffic rights came to be settled by bilateral agreements between states;

- control of capacities and frequencies was subject to inter-airline or bilateral state agreements;

- $\quad$ tariffs came to be set by the International Air Transport Association (IATA).

It is to be noted that in this framework, all the essential economic decisions, that is on entry (traffic rights), on quantities and on pricing are ruled by either governments or suppliers (or their representatives). Whereas many bilaterals had quite a protectionist flavour, the US and the UK took a step towards a somewhat more relaxed bilateral by signing the Bermuda agreement in 1946, significant because it functioned as a reference point for future agreements. It increased the availability of fifth freedom rights (see the appendix 'Freedoms of the air') and put an end to capacity and frequency controls. However, the Bermuda agreement (and thereby the majority of bilaterals) did explicitly conclude that tariffs would be set by IATA procedures. ${ }^{1}$

\footnotetext{
${ }^{1}$ Doganis (1995) points out that this was a major compromise for the US, under whose domestic anti-trust laws such pricefixing was actually illegal.
} 
After the US signed its domestic Airline Deregulation Act in 1978, the international regulatory system came under pressure. The turnaround in US aviation policy resulted in a number of bilateral negotiations at the end of the 1970s, aimed at a general international deregulation. This process of renegotiation resulted in a gradual liberalization on routes to and from the US, and this in turn affected bilaterals between other countries, e.g. the UK-Canada agreement (1987) and the UK-Netherlands bilateral (1984). Liberalization was, however, mostly uncoordinated and localized: no country tried to renegotiate its bilaterals as eagerly and systematically as the US.

\section{European Deregulation ${ }^{2}$}

The European situation was, up till the second half of the 1980s, characterized by rather restricted bilaterals with many similar features. A typical bilateral consisted of market sharing between the two countries flag carriers, often with capacity control, revenue pooling and fare agreements (Button 1996). ${ }^{3}$ It is therefore fair to say that, from the 1980 s onwards, most intra-European airline markets were under much more stringent regulation than the domestic and international markets served by US carriers.

Deregulation between EU member states took place in two major ways: firstly by liberalization of bilaterals between individual states. The above mentioned agreement between the UK and the Netherlands set the standard for a truely liberal bilateral; while not all subsequently renegotiated bilaterals went as far, all of them introduced multiple designation and often some other liberal characteristics as mentioned in table 1 below. ${ }^{4}$

\footnotetext{
${ }^{2}$ The focus will be here on liberalization of the internal market, i.e., on intra-union route-markets. For the 'external dimension', see e.g. Doganis (1995, pp.89-92).

${ }^{3}$ Button states that in 1987 , only 48 out of 988 intra-Union routes enjoyed multiple designation, while over 90 percent of bilaterals involved capacity control and revenue pooling.

${ }^{4}$ Taken from Doganis (1995, p.80).
} 


\begin{tabular}{|c|c|c|c|}
\hline & Traditional Bilaterals & Liberalized Bilaterals & EU 1993 Package \\
\hline Airlines & $\begin{array}{l}\text { One designated airline per } \\
\text { route from each state }\end{array}$ & Multiple designation & $\begin{array}{l}\text { Common airline licencing criteria } \\
\text { in all EU countries; no distinction } \\
\text { between scheduled and non- } \\
\text { scheduled services }\end{array}$ \\
\hline Routes & $\begin{array}{l}\text { Only routes specified in } \\
\text { bilateral }\end{array}$ & $\begin{array}{l}\text { Open market access, flying on } \\
\text { any route between two states }\end{array}$ & $\begin{array}{l}\text { Open market access throughout } \\
\text { EU; domestic cabotage restricted } \\
\text { until } 1997\end{array}$ \\
\hline Capacity & 50:50 capacity sharing & No capacity control & Capacity sharing eliminated \\
\hline Fares & $\begin{array}{l}\text { Approval of both } \\
\text { governments needed, } \\
\text { negotiated through IATA }\end{array}$ & $\begin{array}{l}\text { Double disapproval: fares } \\
\text { only rejected if both } \\
\text { governments disapprove }\end{array}$ & $\begin{array}{l}\text { Free pricing; only very limited } \\
\text { double disapproval and } \\
\text { safeguards against predatory } \\
\text { pricing }\end{array}$ \\
\hline
\end{tabular}

Secondly, the European Union began to develop a deregulatory aviation policy in the late 1980s. Unlike the rigorous deregulation in the US, European deregulation is proceeding step by step. So far, three major 'steps', in the form of the well known deregulation packages have been taken. The first step in this process of gradual liberalization was the 1987 package, in which the transport ministers explicitly agreed upon the application of the competition articles in the Treaty of Rome to the airline industry. ${ }^{5}$ The European Commission had the power to grant exemptions to the rules, and it was clear that many inter-airline agreements on capacity sharing, tariffs, and revenue-pooling would be illegal without them. The granting of

\footnotetext{
${ }^{5}$ The two articles of particular importance are: Article 85, which prohibits anti-competitive agreements and concerted practices that reduce or distort competition, and Article 86, which prohibits abuse of a dominant position that affects trade between EU member states.
} 
exemptions to certain important categories of agreements ${ }^{6}$ reflects the gradual approach taken by the Commission so as to persuade member states to accept progressive future liberalization: all exemptions were of limited duration, and in the successive packages, the liberalizing measures became more and more significant. The most important characteristics of the third EU aviation package (effective 1 January 1993) are summarized in table $1 .^{7}$

\section{The Effects of Deregulation}

In cases where economic regulation acts as a barrier to entry and exit in markets, one can make a broad distinction between static and dynamic effects. In a static sense, the absence of competition confers a degree of monopoly power to the firms in the industry, and theory predicts lower output and higher prices than in an unregulated and competitive environment. In a dynamic sense, regulation may often prohibit innovation and the optimization of processes through competition in an industry, so that, compared with a competitive situation, service quality and costs may be lower and higher respectively. Taking these two effects high prices and high costs in a protected market - together, one may end up in a situation where regulation does not result in high profits. Such a characterization seems to be relevant for the European airline industry.

The effects of deregulation in the airline industry can be described in terms of the above distinction: evidence from a number of deregulated markets, e.g. the North Atlantic or the UK-Netherlands liberalization, shows that new firms entered the market and capacity increased significantly. As indicated above, deregulation often involved (greater) pricing freedom and therefore caused downward pressure on prices and yields. In terms of dynamic impact, the change in carriers' route structures is generally seen as one of the most significant consequences of deregulation in the US (e.g. Morrison and Winston, 1985). Starting with this

\footnotetext{
${ }^{6}$ These were (Button and Swann, 1989): (1) agreements on capacity co-ordination, revenues sharing, tariffs, and slot allocation; (2) agreements on Computer Reservation Systems; (3) agreements on ground handling services.

7 There are extensive reviews of the contents of the various packages in the literature: see, e.g., Button and Swann (1989), Doganis (1995), Stasinopoulos (1993, 1992), and Daniel and Stasinopoulos (1990).
} 
dynamic effect, we will take a closer look at both types of effects in this section. ${ }^{8}$

\subsection{Route Network Structure}

Under a regulated system, like in the US before 1978, airlines may often have to operate a point-to-point network because of route restrictions. As a result of airline deregulation, however, all the major US carriers developed a socalled

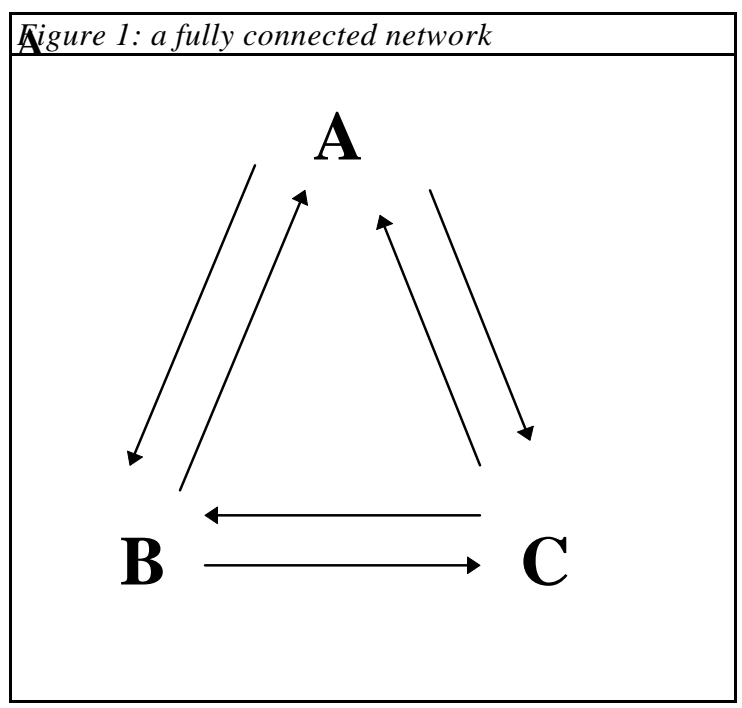
'hub-and-spoke' network. Most city pairs are no longer serviced directly, but passengers are flown to the centre ('hub') of a starshaped network first, and then take a connecting flight to their destination. This crucial shift in operations can be explained in terms of cost considerations and demand conditions (Morrison and Winston, 1985). ${ }^{9}$ Some intuition of the economic motivation for such route restructuring can be obtained using a very simple model.

Consider the three point network in figure 1. Under regulation, a designated carrier has the right to fly passengers from point to point in the network ${ }^{10}$. For simplicity of exposition, suppose each point in the network has the same, constant demand for air transport to each of the other points in the network, say $\alpha$ per day. In the regulated situation, an airline may meet this demand by operating six direct flights per day, as indicated by the arrows.

If the industry is deregulated and the airline is allowed to fly passengers on any route in the network, it may consider operating a hub-and -spoke (HS) network in stead of the current

\footnotetext{
${ }^{8}$ It is fair to say that the route structure effect is less important in Europe. One must assume that, given the low profit levels before deregulation, the extra revenues caused by protective regulation were absorbed by high input costs c.q. low productivity.

${ }^{9} \mathrm{~A}$ further explanation of the phenomenon based on strategic behaviour by airlines is made by Berechman et al. (1994). We will not make use of their results here.

${ }^{10}$ This may, for example, illustrate a situation where an airline from country A has third and fourth freedom rights on the AB and $\mathrm{AC}$ routes, fifth freedom rights on $\mathrm{BC}$, but no sixth freedom rights to fly $\mathrm{BC}$ passengers via $\mathrm{A}$.
} 
fully connected (FC) network; assuming that A is the hub located in the home country, this would mean discontinuing the direct connection $\mathrm{BC}$, and flying these passengers through $\mathrm{A}$. What would be the advantages of such a change in operations? Firstly, there are cost considerations. Assuming unchanged demand and a capacity of aircraft larger than or equal to $2 \alpha$ (i.e., the loadfactor under regulation was smaller than or equal to .50), the airline could simply cut the two BC flights per day and, with appreciably higher loadfactors, meet the same origin-destination transport demand. ${ }^{11}$ Assuming no extra costs associated with the greater number of passengers to be handled at $\mathrm{A}$, the airline saves the marginal costs of the two flights on the $\mathrm{BC}$ route market.

However, BC travelers may not like the extra time and effort needed for the detour via $A$. Therefore, the above cost savings have to be compared with a possible loss of demand. In the words of Morrison and Winston (1985, p.59), "... adoption of a hub-and-spoke route structure is warranted if scope economies are sufficient to offset any losses in revenue". Economies of scope are the cost savings due to the changed route structure, and depend on more efficient aircraft utilization (higher load factors in the example) or, otherwise, the economies associated with larger aircraft size. At the same time, the airline may use the saved capacity in order to increase frequency, and thereby attract extra travelers. ${ }^{12}$ Revenue losses depend on travel time changes, frequency changes and the relevant demand elasticities. ${ }^{13}$

A number of extensions and complications may be added to the simple model outlined above. Firstly, there are certain cost penalties associated with the operation of a HS network. Most importantly, passenger handling costs are higher, as connecting passengers board and disembark twice in stead of once. Also, the above model simply eliminates two flights: however, when capacity restrictions are present and / or frequencies are increased to attract passengers, a HS network will generally involve more landings and take-offs, which

\footnotetext{
${ }^{11}$ Likewise, assuming the airline disposes of a fleet consisting of varied aircraft size, it might achieve this schedule by reallocating aircraft over its network.

${ }^{12}$ According to Morrison and Winston (1985), increased frequencies have been the most important welfare improving consequence of airline deregulation in the US

${ }^{13}$ The latter is illustrated by comparing airline deregulation and intercity bus deregulation: because time losses in a HS network would be very large for bus transport, a deregulated network for intercity bus transport is likely to be linear rather than 'star-shaped'.
} 
increases unit costs and landing charge expenses. Furthermore, in order to make the HS system work, flights from the various spokes have to meet at the hub at approximately the same time. The process involving a wave of arrivals followed shortly by a wave of departures is called a complex, and should take a minimum of transfer time. The peaks in activity experienced by hub airports ask for costly extra handling capacity. It has already been indicated, however, that cost savings occur due to improved aircraft utilization. In reality, this is likely to occur through economies of vehicle size: unit costs are a decreasing function of size.

Furthermore, gains on the demand side deserve some more attention. An airline operating a somewhat more elaborate network than the one in the example, is able to cause a dramatic increase in the number of city-pair markets operated by switching to a HS network: if a hub has $n$ links, the number of markets connected via the hub equals $n(n-1) / 2$, so the number of services offered in a HS network is a quadratic function of the number of spokes. One could say, given the number of links operated, a HS network maximizes the number of OD-markets served.

Finally, a remark should be made about hub-and-spoke networks as strategic advantages of incumbent carriers vis-a-vis potential entrants. As is argued by Berechman et al. (1994), incumbents use hub-and-spoke networks as entry deterring instruments. Also, hub dominance enables carriers to charge higher prices and earning a monopoly rent on routes ending at the hub (Barrett 1992). This line of reasoning helps to explain the twin development of HS networks on the one hand, and the highly oligopolistic character of the US airline industry on the other.

In conclusion, one should try to establish the overall effect on an airline's profit of switching from a FC to a HS network. Notwithstanding the extra costs associated with the operation of a HS network, the advantages are significant in terms of (a) more efficient capital / fleet utilization, (b) higher market share by offering increased frequency and more destinations, and (c) the strategic advantages of hub airport dominance. Evidence from the rigourously deregulated US airline industry, where in the period immediately after deregulation " ... hub- 
and-spoke routing has increased by about 50 percent" (Berechman et al. 1994, p.1) suggests that airlines' benefits of operating HS networks outweigh the costs. In practical terms, this suggests that airline deregulation will induce shorter routes, higher frequencies, probably larger aircraft sizes and more intense peak traffic at airports; also, hub dominance may confer monopolistic power to incumbent carriers.

\subsection{Pricing and Market Structure}

In this section, we will disregard the operational changes outlined above, and compare the (static) effects of deregulation on competition in a given market. Making a few simple assumptions on behaviour under the respective regulatory regimes, economic theory suggests a number of straightforward results regarding the market equilibrium under deregulation. Given that deregulation liberalizes pricing and entry, one of those results and indeed one of the expectations and goals of deregulation (e.g. Kahn, 1988), is a decline in fares due to (more intense) competition.

Such a decline in (average) fares has been shown theoretically by Dresner and Tretheway (1992). They distinguish between (traditional) regulated bilateral agreements, under which prices were fixed by governmental authority, and competitive or liberal agreements. They assume that under the former, carriers collude and fix prices so as to maximize joint profits. Dresner and Tretheway assume duopolists to display Bertrand pricing behaviour, implying that price competition leads to marginal cost pricing; thus, it can easily be shown that prices will decrease after deregulation. It should, however, be noted that the Bertrand model with its marginal cost pricing and zero profit outcome, is not completely satisfactory; in the airline industry as in other industries, duopolists are observed to earn positive profits. This socalled Bertrand paradox can be solved theoretically in a number of ways (Tirole 1988). One can introduce longer time horizon than the 'one-shot-game' setting of the model, i.e., carriers do not engage in price wars because short-run gains are offset by profits foregone in the longer run. Also, if consumers do not view competitors' products as perfect sustitutes, price competition is relaxed. Finally, even when consumers do not differentiate between the seats of two competing airlines, one can solve the paradox by introducing capacity constraints. In a multiperiod variant of the Edgeworth model, Dudey 
(1992) shows that when one of the duopolists has capacity less than market demand, and the other has capacity at least equal to market demand, the optimal strategy for the second duopolist is to let the other sell out first, and after that charge the profit maximizing price to the rest of the market. If the second duopolist would not do so, price competition would lead to zero profits for both firms. Together with the presence of a certain degree of product differentiation, this may explain the absence of price wars and marginal cost pricing in a number of airline markets.

Another way to deal with the strong assumptions underlying the basic oligopoly models is to empirically estimate measures of competitive behaviour (known as conduct parameters or conjectural variations) in deregulated airline markets using a more general model (Brander and Zhang, 1990; Oum et al., 1993). The latter study shows that for duopoly markets of American Airlines and United Airlines, the conduct parameters are lower (airlines behave more competitively) as distances rise, as the combined market share declines and as more fringe competitiors are present. One conclusion is that airlines adjust their pricing strategies to competitive conditions in each route market. The above studies, however, also show that the conduct parameters for these duopolists are, on average, much closer to zero (Cournot behaviour) than to minus one (competitive pricing). We may conclude that there are both theoretical and empirical arguments rejecting the hypothesis of competitive, that is, marginal cost pricing. However, theory and empirical evidence show that average fares have decreased as a result of deregulation.

A closely related question is whether entry took place. Even if the above models show oligopoly pricing above competitive levels, theory predicts prices to decline as new firms enter the market (Martin, 1993). Entry is likely to occur when the potential entrant expects positive returns to his investment; we may therefore assume that entry will occur if there are positive profits in the industry, the entrant is likely to obtain a certain share of the market and the sunk costs are not 'too' high.

The empirical evidence on this issue is mixed: whereas capacity greatly increased immediately after liberalization in a number of cases (e.g. on many US domestic routes and 
the North Atlantic), reconcentration in the medium term has been widespread. ${ }^{14}$ For Europe, the situation is different: as Doganis (1994) points out, European carriers, aware of the benefits of large scale operations (economies of scope), have been trying to widen their market base since the mid 1980s, in order to cope with the new competitive environment. The result of scope oriented strategies like takeovers on the domestic market, acquisition of shares in other European carriers and seeking global alliances has been a growing concentration in the European airline industry before the 1993 package. As a result, hardly any new entrant has emerged on the European markets. Evidence shows that the number of competitors on the busiest European routes has been either stable or declined since the late 1980s. Such a conclusion is consistent with the now widely held view that the deregulated airline industry is not perfectly contestable, ${ }^{15}$ or, that the industry is characterized by important barriers to entry.

A number of authors have indicated barriers which render airline markets difficult to enter (imperfectly contestable) after deregulation. First, Barrett (1992) and Levine (in Keeler 1991) point to the possibility of hub airport dominance by incumbents, making entry very difficult or impossible by manipulation of airport capacity allocation. Morrison and Winston (1990) demonstrate that the depressing effect of potential competition on fares is much lower for routes with a slot-controlled (congested) airport than for routes without capacity constraints.

Secondly, entry entails costs of communicating complex information and of establishing reputation, which are characterized by economies of scale and scope. Furthermore, travel agencies sell tickets for the entire US air travel system through a few computer reservation systems $(\mathrm{CRS})^{16}$, which are owned by only a few airlines who can use it to supply biassed information in their favour. Access to these systems for entrants is very costly. Ground handling monopolies have the same effect.

Apart from these 'structural' barriers to contestability, strategic barriers can be distinguished, viz., anticompetitive mergers and pricing policy (Barrett 1992; Doganis 1994).

\footnotetext{
${ }^{14}$ This has been called the most unpleasant surprise of airline deregulation by Kahn (1988).

${ }^{15}$ For a discussion of the 'theory of contestable markets' in the context of US airline deregulation, see Martin (1993, 315-319).

${ }^{16}$ In Europe, the two major CRSs are owned by a number of different carriers.
} 
Mergers reduce the possibility of price competition, by eliminating the number of independent suppliers in markets. Morrison and Winston (1989) and Borenstein (1990) report significantly higher prices as a result of mergers; in the absence of other competitors, mergers may result in price increases over $12 \% .{ }^{17}$ The use of pricing policy as a strategic instrument may result in collusive pricing in uncontested, oligopolistic markets (although the evidence shown above rejects such a cartel hypothesis), and in the possibility of predatory pricing in markets that are contested. Without testing empirically all the above barriers to contestability here, the literature suggests that they are quite substantial and indeed confer market power to airlines.

The overall conclusion on pricing and market structure reads that deregulation brought considerable benefits to consumers by lowering average real fares, while remaining entry barriers allow carriers to keep prices above competitive levels in oligopolistic markets. Without going into the size of the specific demand elasticities, this does suggest a positive effect on demand for air transport.

\section{Environmental effects of deregulation.}

Particular features of environmental problems caused by aviation are that the sources are mobile so that they cannot be simply attached to a particular location or even a country, and that the altitude of the emission influences the dispersion pattern.

Aviation has environmental effects at various scales. Some of them are local and concern noise near airports and emissions of pollutants by aircraft while being at airports or during the landing and take-off cycle. Among these emissions are those of VOC due to fuelling of aircraft and fuel handling in general, and CO emissions of aircraft while being in the idle and taxi mode due to incomplete combustion. For these pollutants the shares emitted at altitudes lower than $1.5 \mathrm{~km}$ are dominant (50 to $80 \%$ ). For other pollutants such as $\mathrm{NO}_{\mathrm{x}}$

\footnotetext{
${ }^{17}$ However, Morrison and Winston (1989) evaluate total welfare effects of mergers, including e.g. decreased travel time, and conclude that half of the mergers reduce travelers' welfare, while half of the mergers result in an increase.
} 
and $\mathrm{SO}_{2}$ these shares are clearly lower (20 to $40 \%$ ).

At a larger spatial scale (regional/national/continental) are emissions due to climbing/approaching and cruising. These emissions take place in the forms of $\mathrm{CO}_{2}, \mathrm{NO}_{\mathrm{x}}$, $\mathrm{SO}_{2}, \mathrm{CH}, \mathrm{CO}, \mathrm{VOC}$ and other polluting gases.

At a global scale emissions are important that take place in the stratosphere (the layer above about $12 \mathrm{~km}$ where also the Ozone layer is located). Since most aircraft has cruise levels at about 10 to $12 \mathrm{~km}$ (not far away from the stratosphere), a non-negligible part of the aircraft effluents is indeed emitted in the stratosphere (cf. Olivier, 1991).

Table 2 gives an impression of current emission levels due to aviation. The largest contributions in this table concern $\mathrm{CO}_{2}$ and $\mathrm{NO}_{\mathrm{x}}$. Although the present shares are limited, one must be aware that aviation is among the sectors in the world with a high growth rate (more than 5\% at an annual basis). This means that the aviation share of emissions tends to increase. 
Table 2. Emissions by aviation at world level, 1990.

\begin{tabular}{||l|l|l||}
\hline type of emission & $\begin{array}{l}\text { emission by aircraft (mln } \\
\text { tons) }\end{array}$ & $\begin{array}{l}\text { share in global emissions due } \\
\text { to energy use (\%) }\end{array}$ \\
\hline $\mathrm{CO}_{2}$ & 556 & 3 \\
\hline $\mathrm{H}_{2} \mathrm{O}$ & 219 &. \\
\hline $\mathrm{SO}_{2}$ & .19 & .1 \\
\hline $\mathrm{NO}$ & $1.8-4.6$ & 4 \\
\hline $\mathrm{CO}$ & $.27-.79$ & .2 \\
\hline $\mathrm{CH}$ & $.09-.27$ &. \\
\hline
\end{tabular}

Source: Fransen and Peper (1993).

As explained in the preceding sections, deregulation may have far-reaching effects on the volume and structure of operations of the airline industry. Hence, it will also influence the environmental impacts of aviation. An important consideration in this respect is that aviation due to its international character has a rather privileged position in terms of taxation. Not only do international airports and airlines benefit from tax free shopping facilities, but especially the fact that value added taxes on international airline tickets and excise taxes on kerosine for international flights are zero leads to an absence of financial incentives to correct for air traffic externalities. Thus, where welfare gains may be expected from a deregulation of aviation (section 4), there is also the danger of the generation of excessive external costs.

The effects of deregulation on emissions take place in various ways. First, the increase in the level of competition has a depressing impact on fares. Since the price elasticity 
of demand for air traffic is substantial, this will also have a substantial effect on the volume of traffic. This clearly has an unfavourable effect on overall emissions.

Next, a more competitive environment for the aviation industry will lead to a stronger drive for improvement of fuel efficiency. Efforts to improve fuel efficiency will reduce emissions of $\mathrm{CO}_{2}$ and possibly also of other gases. However, there may also be conflicts between improving energy efficiency and reducing environmental damage. For example, Somerville (1993) notes that the very technology that has led to improvements in fuel efficiency leads to increased $\mathrm{NO}_{\mathrm{x}}$ emissions. Where the drive for cost reductions induced by deregulation leads to higher load factors, there are certainly gains to be expected in terms of emissions per passenger kilometre.

Concerning the environmental effects of the introduction of hub and spoke structures, we will formulate a simple linear relationship. Let $\mathrm{E}$ be the volume of emissions, $\mathrm{D}$ the distance between two airports, $Q$ the maximum capacity of a plane, and $q$ the actual number of passengers $(\mathrm{q}<\mathrm{Q})$. We distinguish two regimes:

1. approaching, landing, taxiing, being idle, take-off, climbing, and

2. cruising.

In both regimes the emission level consists of a constant, a capacity dependent part and a passenger volume dependent part. In addition, distance plays a role in the second regime: the environmental impacts are assumed to be proportional to flight distance. Thus we arrive at ${ }^{18}$ :

$$
E(D, Q, q)=\left(a_{0}+a_{1} Q+a_{2} q\right)+\left(b_{0}+b_{1} Q+b_{2} q\right) D \quad q<Q
$$

where the $\mathrm{a}$ and $\mathrm{b}$ coefficients are all assumed to be positive. Note that a similar specification can be given for the costs $\mathrm{C}$ of providing a transport service ${ }^{19}$ :

\footnotetext{
18 This is obviously a simplified specification. For example, since more fuel has to be taken in the case of long distance trips, this will increase the weight of the aircraft and hence the CQ emissions both during take-off and cruising. Thus we would arrive at a non-linear form where coefficients would depend on the distance of a trip.

19 Also for the cost function non-linear forms could be proposed but we give priority to a simple presentation.
} 


$$
\mathrm{C}(\mathrm{D}, \mathrm{Q}, \mathrm{q})=\left(\mathrm{c}_{0}+\mathrm{c}_{1} \mathrm{Q}+\mathrm{c}_{2} \mathrm{q}\right)+\left(\mathrm{d}_{0}+\mathrm{d}_{1} \mathrm{Q}+\mathrm{d}_{2} \mathrm{q}\right) \mathrm{D} \quad \mathrm{q}<\mathrm{Q}
$$

where again the $\mathrm{c}$ and $\mathrm{d}$ coefficients are positive. Note, that in the absence of economies of density and economies of aircraft size the coefficients $\mathrm{c}_{0}, \mathrm{c}_{1}, \mathrm{~d}_{0}$ and $\mathrm{d}_{1}$ would be equal to zero. In that case hub and spoke networks would not make sense Empirical estimates of these coefficients indicate that they are substantial (cf. Brander et al., 1991).

The E formula can be used to illustrate the environmental consequences of a hub and spoke network replacing the fully connected network given in Figure 1.

Let us assume that traffic volumes are identical among pairs of destinations, and that they remain the same after the transition from the FC to the HS network. Then the total environmental impact in the FC network is (case 0 ):

$$
E_{0}(F C)=6\left(a_{0}+a_{1} Q+a_{2} q\right)+6\left(b_{0}+b_{1} Q+b_{2} q\right) D
$$

Assume that the load factor $\mathrm{q} / \mathrm{Q}$ is smaller than .50 so that in the HS network no additional flights are needed. This leads to:

$$
\mathrm{E}_{0}(\mathrm{HS})=4\left(\mathrm{a}_{0}+\mathrm{a}_{1} \mathrm{Q}+\mathrm{a}_{2} 2 \mathrm{q}\right)+4\left(\mathrm{~b}_{0}+\mathrm{b}_{1} \mathrm{Q}+\mathrm{b}_{2} 2 \mathrm{q}\right) \mathrm{D}
$$

It is not difficult to see that $\mathrm{E}_{0}(\mathrm{HS})$ is smaller than $\mathrm{E}_{0}(\mathrm{FC})$ when the constant terms $\mathrm{a}_{0}$ and $\mathrm{b}_{0}$ are of some magnitude. In addition, even when these constants would be zero, it would suffice that $a_{1}>=a_{2}$, and $b_{1}>=b_{2}$, to guarantee that $E_{0}(H S)<E_{0}(F C)$. Note for example that in the case of noise these conditions are easily met: $a_{2}$ is near to zero and $b_{1}$ and $b_{2}$ are both equal to zero.

The above result obviously depends on the assumption that in the FC network low load factors are prevailing. An alternative extreme case would be that we take the least favourable situation for the creation of a HS network, namely the case where with the FC network aircraft would be used at full capacity for all connections $(q=Q)$ :

$$
\mathrm{E}_{1}(\mathrm{FC})=6\left(\mathrm{a}_{0}+\mathrm{a}_{1} \mathrm{Q}+\mathrm{a}_{2} \mathrm{Q}\right)+6\left(\mathrm{~b}_{0}+\mathrm{b}_{1} \mathrm{Q}+\mathrm{b}_{2} \mathrm{Q}\right) \mathrm{D}
$$


In this case the HS network with the same type of aircraft would lead to:

$$
\mathrm{E}_{1}(\mathrm{HS})=8\left(\mathrm{a}_{0}+\mathrm{a}_{1} \mathrm{Q}+\mathrm{a}_{2} \mathrm{Q}\right)+8\left(\mathrm{~b}_{0}+\mathrm{b}_{1} \mathrm{Q}+\mathrm{b}_{2} \mathrm{Q}\right) \mathrm{D}
$$

Since in this special case there are neither gains in load factors, nor economies of aircraft size which are exploited, it is clear that the hub and spoke system is inferior to the fully connected system. The inferiority holds true both from an environmental perspective as shown here, but also from a cost perspective (given the similarity of the $\mathrm{E}$ and $\mathrm{C}$ functions). The only advantage the (customers of the) airline industry might have with a HS network in this particular case is that the frequency of flights is doubled. This has to be traded off against the higher costs involved and the inconvenience of the transit at the hub.

Another possibility would be that the firm responds by using larger aircraft with a capacity of 2Q. In that case the environmental impact of a HS network would be:

$$
\mathrm{E}_{2}(\mathrm{HS})=4\left(\mathrm{a}_{0}+\mathrm{a}_{1} 2 \mathrm{Q}+\mathrm{a}_{2} 2 \mathrm{Q}\right)+4\left(\mathrm{~b}_{0}+\mathrm{b}_{1} 2 \mathrm{Q}+\mathrm{b}_{2} 2 \mathrm{Q}\right) \mathrm{D}
$$

Clearly, we find that the exploitation of economies of aircraft size is favourable for the environment: $\mathrm{E}_{2}(\mathrm{HS})<\mathrm{E}_{1}(\mathrm{HS})$. But whether this is enough in this special case to make the HS network more environmentally friendly than the $\mathrm{FC}$ network $\left[\mathrm{E}_{2}(\mathrm{HS})<\mathrm{E}_{1}(\mathrm{FC})\right]$ strongly depends on the coefficients.

An interesting question is to what extent the preference for HS networks from a private costs perspective according to the specification given above translates into a preference for HS from an environmental viewpoint. Such a correspondence would mean that the ratios of the a and $\mathrm{b}$ coefficients in the $\mathrm{E}$ function would be similar to the ratios of the $\mathrm{c}$ and $\mathrm{d}$ coefficients in the Cost function. If such a correspondence would exist it would imply that cost minimization considerations leading to the formation of HS networks would run parallel to the minimization of environmental impacts. There are good reasons to expect such a similarity for certain environmental impacts. For example, energy consumption is not only a cost component, but also proportional to $\mathrm{CO}_{2}$ emissions. However, for other types of emissions 
such a similarity is not so evident. For example, we noted already above, that emissions like $\mathrm{CO}$ and VOC primarily take place during the first regime, whilst emissions of $\mathrm{NO}_{\mathrm{x}}$ and $\mathrm{SO}_{2}$ especially take place during the cruise phase. This means that for the various types of emissions different patterns will be found for the coefficients.

We conclude that these coefficient patterns of the external costs are an interesting subject for further research. In case the results would point at clear differences in the patterns for cost coefficients and environmental coefficients there might be a tendency that an introduction of Pigovian taxes related to the pollutants would shift the network structures away from the hub and spoke pattern.

An issue not yet addressed in the above discussion concerns equity. The environmental burden implied by the cost functions presented above is not evenly spread in space. More in particular, the local effects produced during regime 1 are concentrated in areas near airports. The transition from FC to HS in case 0 leads to an improvement for the non-hub airports, while the situation in the hub airport (slightly) deteriorates. In a similar fashion we find for case 1 that the local environmental situation worsens in the hub and remains the same in the non-hub airports as a consequence of the transition from the FC to the $\mathrm{HS}_{1}$ network. With the $\mathrm{HS}_{2}$ solution the situation in the hub would deteriorate and in the non-hub airports it would improve. Thus, a general tendency can be observed that the environmental situation in the hub deteriorates relative to the situation in the other airports as a consequence of the introduction of hub and spoke networks.

We finish this section by pointing at two interesting topics as subjects for further research. The first topic concerns local airport taxes as an instrument to correct for air transport externalities; an issue is to what extent such taxes will discourage the emergence of extremely dominant hub airports.

The second topic concerns the possibility that regions around hub airports receive a compensation for the negative environmental externality in the form of a positive externality: a high level of international accessibility leading to the location of internationally oriented economic activities such as corporate headquarters, distribution centres, and offices of international organizations. 


\section{Conclusions.}

Deregulation in the US airline sector has had a strong impact on fares, network structures, and the level of concentration. The overall conclusion reads that in the US consumer welfare has increased owing to the decrease in fares and the increases in frequencies. However, since the airline market is not perfectly contestable after the deregulation, there remains scope for oligopolistic profits. For the European airline sector similar results may be expected, but effects on network structures will probably be smaller because all major European airlines do already operate hub and spoke networks. Nevertheless, deregulation may lead to a shift into the direction of a smaller number of major hubs associated with a small number of dominating airlines.

An important aspect of deregulation which has not received much attention in the literature concerns the external costs. These costs are especially important since, in contrast with other transport modes, the use of Pigovian taxes in aviation has been very limited up to now $^{20}$. Major effects of deregulation on the environment would be a decrease of fares (stimulating an increase in traffic volumes which is unfavourable for the environment) and an increase of load factors (leading to a higher efficiency in fuel use and thus also in $\mathrm{CO}_{2}$ emissions per traveller kilometre). In the paper we also address a number of issues related to the effects of the introduction of hub and spoke networks on the environment. The question whether this effect is favourable appears to depend on a good number of coefficients, but there is some reason to believe that the effect is favourable for most types of pollutants as long as we may assume that the total number of trips remains constant. However, in terms of equity an unfavourable development takes place for hub airports where local environmental conditions worsen relative to the situation in non-hub airports.

\footnotetext{
${ }^{20}$ An investigation of the environmental impacts of taxes on kerosine use is given by Olivier (1995).
} 


\section{REFERENCES}

BARRETT, S.D. (1992), Barriers to Contestability in the Deregulated European Aviation Market. Transportation Research 26A(2), 159-165.

Berechman, J., S. Poddar, And O. Shy (1995), Network Structure and Entry in the Deregulated Airline Industry. CORE Discussion Paper 9464, Louvain-la-Neuve.

BRANDER, J.A. AND A. ZHANG (1990), Market conduct in the airline industry: an empirical investigation. Rand Journal of Economics, 21(4), 567-583.

BRANDER, J.R., B.A. COOK AND J.E. ROWCROFT (1991), Entry, exclusion, and expulsion in a single hub airport system, Transportation Research Record, 1214, 27-36.

ButTon, K.J. (1996), Aviation Deregulation in the European Union: Do Actors Learn in the Regulation Game? Contemporary Economic Policy 14(1), 70-80.

Button, K.J. AND D. Swann (1996), European Community Airlines - Deregulation and its Problems. Journal of Common Market Studies 27(4), 259-282.

DoganIS, R. (1995), Flying Off Course: The Economics of International Airlines. Routledge, New York.

DogAnIS, R. (1994), The Impact of Liberalization on European Airline Strategies and Operations. Journal of Air Transport Management 1 (1), 15-25.

Dresner, M. AND M.W. Tretheway (1992), Modelling and testing the effect of market structure on price: the case of internationale air transport. The Journal of Transport Economics and Policy, 26(2), 171-184.

Dudey, M. (1992), Dynamic Edgeworth-Bertrand Competition. Quarterly Journal of Economics 107, 1461-1477.

FRANSEN, W. AND J.A. PEPER (1993), Atmospheric effects of aircraft emissions, National Aerospace Laboratory, Amsterdam.

MARTin, S. (1993), Advanced Industrial Economics. Blackwell, Cambridge (MA).

MORRISON, S.A., AND C. WINSTON (1985), Intercity Transportation Route Structures under Deregulation: Some Assessments Motivated by the Airline Experience. American Economic Review, Papers and Proceedings 75(2), 57-61.

MorRison, S.A., AND C. Winston (1989), Enhancing the Performance of the Deregulated 
Air Transportation System. Brookings Papers on Economic Activity: Microeconomics, 1989, $61-122$.

OLIVIER, J. (1991), Inventory of aircraft emissions: a review of recent literature, National Institute of Public Health and the Environment, Bilthoven.

OLIVIER, J. (1995), Scenarios for global emissions from air traffic, National Institute of Public Health and the Environment, Bilthoven.

SOMERVILlE, H. (1993), The airline's industry perspective, in: D. Banister and K. Button (eds.), Transport, the environment and sustainable development, Chapman and Hall, London, pp. 161-174.

Stasinopoulos, D. (1993), The Third Phase of Liberalisation in Community Aviation and the Need for Supplementary Measures. Journal of Transport Economics and Policy 27(3), 323-328.

Stasinopoulos, D. (1992), The Second Aviation Package of the European Community. Journal of Transport Economics and Policy 26(1), 83-87.

TIROLE, J. (1988), The Theory of Industrial Organization. Cambridge, MA: The MIT Press. Vincent, D. And D. STASinopoulos (1992), The Aviation Policy of the European Community. Journal of Transport Economics and Policy 24(1), 95-100.

Winston, C. (1993), Economic Deregulation: Days of Reckoning for Microeconomists.

Journal of Economic Literature, 31, 1263-1289. 


\section{APPENDIX}

FREEDOMS OF THE AIR (from Doganis, 1995, p. 347)

$>$ Negotiated in bilateral air services agreements:

First Freedom: The right to fly over another country without landing.

Second Freedom: The right to make a landing for technical reasons without picking up / setting down revenue traffic.

Third Freedom: The right to carry revenue traffic from your own country (A) to the country (B) of your treaty partner.

Fourth Freedom: The right to carry traffic from country B back to your own country A. Fifth Freedom: The right of an airline from country A to carry revenue traffic between country B and other countries such as C or D. This freedom cannot be used unless countries $\mathrm{C}$ or D also agree.

$>$ Supplementary:

Sixth Freedom: The use by an airline of country A of two sets of third and fourth freedom rights to carry traffic between two other countries while using its base at A as a transit point. An example is the traffic in figure 1 between $\mathrm{B}$ and $\mathrm{C}$ through the (home) base $\mathrm{A}$. 